International Journal of Current Advanced Research

ISSN: O: 2319-6475, ISSN: P: 2319 - 6505, Impact Factor: SJIF: 5.995

Available Online at www.journalijcar.org

Volume 6; Issue 3; March 2017; Page No. 2477-2479

DOI: http://dx.doi.org/10.24327/ijcar.2017.2479.0032

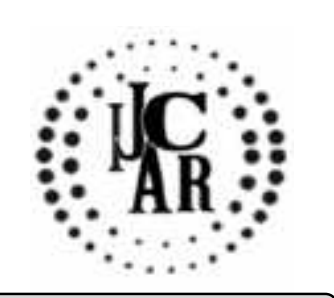

Research Article

\title{
ECTOPIC PREGNANCY IN OROTTA NATIONAL REFERRAL MATERNITY HOSPITAL: FROM JANUARY 1,2009 to DECEMBER 31, 2011
}

\author{
DawitSereke., DawitEstifanos., KifleyesusTedla., BrehaneZekarias and SuasanMarzolf
}

Orotta Post Graduate Medical Education Asmara, Eritrea

\section{A R T I C L E I N F O}

\section{Article History:}

Received $19^{\text {th }}$ December, 2016

Received in revised form $20^{\text {th }}$ January, 2017

Accepted $14^{\text {th }}$ February, 2017

Published online $28^{\text {th }}$ March, 2017 \begin{abstract}
A B S T R A C T
Objectives:-To asses the prevalence of ectopic pregnancy in Orotta Maternity Hospital. To asses some of the risk factors that leads to ectopic pregnancy.

Methods:-Data collection for this study was performed as part of institutional board approved three years retrospective cross-sectional descriptive study of patients admitted in Orotta National Referral Maternity Hospital with the diagnosis of ectopic pregnancies. Patient identification performed through review of prerecorded log book and patient card describing each patient admitted to Gynecology ward. Based on this, Medical records were reviewed and pertinent maternal information was recorded including obstetrics, medical, surgical, social history and demographic information. Pertinent information on the outcome of the problem was also reviewed. Data were entered into computer and analyzed using the STATA 9.

Result: - a study of 49 cases ectopic pregnancy managed over three years period in Orotta National Maternity Referral Hospital was reported. The total number of deliveries in the hospital in the study duration was 30,000. The prevalence of ectopic per 1000 deliveries was 16 . From this study the mean age, gravidity and parity were 30,3 and 2 respectively. The mean gestational age for ectopic pregnancy was 7 weeks. All of the ectopic cases complain of abdominal pain but only $75 \%$ of them have vaginal bleeding. More than $94 \%$ came with ruptured ectopic and needing emergency blood transfusion. It shows that it is one of the commonest gynecological emergencies in the hospital. The usual surgical treatment of cases in our unit was total salpingectomy.

Discussion: - ectopic pregnancy was common in our hospital like in some African countries. Late diagnoses were important findings that should encourage our physician to promote ectopic pregnancy prevention programs and to improve the care given to women with ectopic pregnancy It should be considered a relevant public health indicator in our country, providing an overall picture of the capacity of a health system to deal with the diagnosis and treatment of emergency situations, especially in the field of obstetrics and gynecology.
\end{abstract}

Copyright $\odot 2017$ DawitSereke et al. This is an open access article distributed under the Creative Commons Attribution License, which permits unrestricted use, distribution, and reproduction in any medium, provided the original work is properly cited.

\section{INTRODUCTION}

Ectopic pregnancy (EP) is defined as a pregnancy in which the implantation of the embryo occurs outside the uterine cavity,most frequently in one of the two fallopian tubes or, more rarely, in the abdominal cavity. During the first three months of pregnancy, EP is the leading cause of maternal death in industrialized countries, and possibly the second most frequent cause in developing countries (after abortion complications)(1). EP is derived from the Greek word ektopos, meaning out of place, and it refers to the implantation of a fertilized egg in a location outside of the uterine cavity, including the fallopian tubes, cervix, ovary, cornual region of the uterus, and the abdominal cavity (2).

*Corresponding author: DawitSereke

Orotta Post Graduate Medical Education Asmara, Eritrea
Since 1970, the frequency of EP has increased 6-fold, and it now occurs in $2 \%$ of all pregnancies (2). Multiple factors contribute to the relative risk of ectopic pregnancy. In theory, anything that hampers the migration of the embryo to the endometrial cavity could predispose women to ectopic gestation. Some of the risk factors that are associated with it are pelvic inflammatory disease, history of prior ectopic pregnancy, use of fertility drugs or assisted reproductive technology, use of an intrauterine device, increasing age , smoking, prior abdominal surgery, failure with progestin-only contraception, and ruptured appendix(2).

The diagnosis of EP can be made by noninvasive methods, i.e. sensitive pregnancy tests (in urine and serum), and high resolution transvaginal sonography, which have been integrated in reliable diagnostic algorithms (3). 
The most common extra-uterine location is the fallopian tube, which accounts for 98 percent of all ectopic gestations. Management of these pregnancies has changed dramatically over the years. The guiding principle has become a conservative approach that attempts to save the tube, rather than salpingectomy. However, it is important to remember that hemorrhage from ectopic pregnancy is still the leading cause of pregnancy related maternal death in the first trimester and accounts for 4 to 10 percent of all pregnancy related deaths, despite improved diagnostic methods leading to earlier detection and treatment(4). In one series of 1800 surgically treated cases, the distribution of sites was ampullary $(70 \%)$, isthmic (12\%), fimbrial (11.1\%), ovarian (3.2 percent), interstitial (2.4\%), and abdominal (1.3\%) (4)

Data on EP are rare and often out of date in developingcountries, particularly in Africa. A review of EP in developing Countries from the 1960s to the mid-1980s showed that the incidence of EP was between $0.5 \%$ and $2.3 \%$ of live births inAfrica (5).

There is no any data about the incidence of ectopic pregnancy in Eritrea and there in no any code specifically for ectopic pregnancy in theIDSR. For this reason it is important to study the prevalence of the diseases in Orotta Maternity Hospital for it show the prevalence of the diseases in the country.

\section{LITERATURE REVIEW}

Every year some eight million women suffer pregnancyrelated complications and over half a million die. In developing countries, one woman in 11 may die of pregnancy-related complications compared to one in 5000 in developed countries (6). EP is the leading cause of pregnancy-related death in the first trimester, accounting for $9 \%$ of all pregnancy-related deaths (6).

In one study of the 268 pregnancy-related deaths, $16(6 \%)$ were caused by complications of ectopic pregnancy. Mean age at death was $27( \pm 6)$ years (7). Whilethe incidence of ectopic pregnancy has continued to increase, the case fatality rate has dropped from $69 \%$ in 1876 , to $0.35 \%$ in 1970 , and to $0.05 \%$ in 1986 . The death rate for African American and other minority women remains over double that for white women and the highest death rate occur in the 15- to 19-year-old age group (8)

Whereas ectopic pregnancy is well documented in industrialized countries, little research has been done on this gynecologic emergency in developing countries, especially in African regions. Liskin, reviewing ectopic pregnancy incidence from the 1960s until the middle of the 1980s, reported the highest incidence rates in African countries (between $0.5 \%$ and $2.3 \%$ of live births), whereas low incidence rates were observed in Asia and the Middle East in the same period (between $0.4 \%$ and $0.6 \%$ of live births) (9).

In Madagascar, a hospital-based ectopic pregnancy incidence of $2.9 \%$ (live births) was observed in the island of Nosy Be between 1993 and 1995. In Nigeria (Ile-Ife teaching hospital), the hospital-based incidence of ectopic pregnancy quadrupled between 1977 and 1987 (0.4-1.7\% of live births), and in Gabon (University Medical Center of Libreville) it doubled in a 12 -year period from $1 \%$ in 1977 to $2.3 \%$ in 1989 (9). In the United States, the incidence of ectopic pregnancy increased from $4.5 / 1,000$ pregnancies in 1970 to $19.7 / 1,000$ pregnancies in 1992 (10).

\section{Objective}

1. General objective: To assess the prevalence of ectopic pregnancy in Orotta Maternity Hospital

2. Specific objective-

- To determine the prevalence of the disease

- To assess some of the risk factors that leads to ectopic pregnancy

- To determine main surgical intervention in the hospital.

\section{MATERIALS AND METHODS}

This study was conducted in Orotta National Referral Hospital. The study protocol was reviewed and approved by Institutional Review Board. It was a retrospective crosssectional descriptive study of patients admitted in Orotta National Referral Maternity Hospital with the diagnosis of ectopic pregnancies from Jan 1st 2009 to Dec 31 2011, in Asmara, Eritrea. Patient identification performed through review of prerecorded log book and patient card describing each patient admitted to Gynecology ward with the diagnosis of ectopic pregnancy. Based on this, Medical records were reviewed and pertinent maternal information was recorded including obstetrics, medical, surgical, social history and demographic information.

Pertinent information on the outcome of the problem was also reviewed which includes the type and the location of ectopic, outcome of the operation, the type of operation and blood transfusion rate. The main out come meaures were prevalence of ectopic, risk factors for ectopic, and main surgical intervention in the hospital.

Statistical analysis-Data were entered into computer and analyzed using the STATA 9.

\section{RESULT}

A study of 49 cases ectopic pregnancy managed over three years period in Orotta National Maternity Referral Hospital was reported. The total number of deliveries in the hospital in the study duration was 30,000 . The prevalence of ectopic per 100 deliveries was 1.6. From this study the mean age, gravidity and parity were 30,3 and 2 respectively. The mean gestational age for ectopic pregnancy was 7 weeks (table 1).

Table 1 The mean distribution of ectopic mothers by age parity, gravidity and gestational age in OMNRH, 20092011.

\begin{tabular}{cccccc}
\hline Variable & \multirow{2}{*}{ Observation } & \multirow{2}{*}{ Mean } & $\begin{array}{c}\text { Standard } \\
\text { deviation }\end{array}$ & \multicolumn{2}{c}{ Range } \\
\cline { 5 - 6 } & & & Minimum & Maximum \\
\hline Age & 49 & 30 & 5 & 18 & 46 \\
Gravidity & 49 & 3 & 2 & 1 & 11 \\
Parity & 49 & 2 & 2 & 0 & 8 \\
Gestational age & 49 & 7 & 3 & 4 & 14 \\
\hline
\end{tabular}

Table 2 shows data stratified by age. The two extreme age groups had the lowest percentage of ectopic pregnancy, whereas the age group 21 to 30 had the highest percentage (57\%). Demographic information of ectopic pregnant mother shows $84 \%$ live in ZobaMeakel, $76 \%$ of them are married and $98 \%$ of them are Christians.

In our study, the percentage of patients who presented with ectopic pregnancy with abdominal pain was $100 \%$, amenorrhea $88 \%$ and vaginal bleeding $75 \%$. Abdominal tenderness and/or adnexal tenderness $(100 \%)$ were the most 
common physical findings. From this study most of them didn't have significant risk factors such as history of Evacuation and curettage, pelvic inflammatory disease, infertility, abdominal operation and usage of contraceptive. Ninety eight percent of the cases pregnancy test was positive (table 3).

Table 2- Socio-demographic characteristics of ectopic pregnant women in OMNRH, 2009-2011

\begin{tabular}{ccc}
\hline Variable & Frequency & Percent \\
\hline Address & & \\
Meakel & 41 & 84 \\
Others & 8 & 16 \\
\hline Religion & & \\
\hline Christian & 48 & 98 \\
Muslim & 1 & 2 \\
Age & & \\
$\leq 20$ & 2 & 4.1 \\
$21-25$ & 6 & 12.3 \\
$26-30$ & 22 & 44.9 \\
$31-35$ & 10 & 20.4 \\
$36-40$ & 8 & 16.3 \\
$>41$ & 1 & 2 \\
\hline Marital status & & \\
\hline Married & 37 & 76 \\
Single & 12 & 24 \\
Total & $\mathbf{4 9}$ & $\mathbf{1 0 0}$
\end{tabular}

Table 3 Frequency distribution of ectopic pregnancy based on history, finding, location of ectopic and treatment

\begin{tabular}{|c|c|c|c|}
\hline \multicolumn{2}{|c|}{ Variable } & Frequency & Percentage \\
\hline \multicolumn{2}{|c|}{ Amenorrhea } & 43 & 88 \\
\hline \multicolumn{2}{|c|}{$\begin{array}{l}\text { Abdominal pain and abdominal } \\
\text { tenderness }\end{array}$} & 49 & 100 \\
\hline \multicolumn{2}{|c|}{ Vaginal bleeding } & 37 & 76 \\
\hline \multicolumn{2}{|c|}{ Usage of contraceptive } & 2 & 4 \\
\hline \multicolumn{2}{|c|}{ History of Infertility } & 10 & 20 \\
\hline \multicolumn{2}{|c|}{ History of PID } & 3 & 6 \\
\hline \multicolumn{2}{|c|}{ History of Abdominal operation } & 1 & 2 \\
\hline \multicolumn{2}{|c|}{ History of E and C } & 14 & 29 \\
\hline \multirow{4}{*}{ Location } & Ampullary & 40 & 82 \\
\hline & Isthmus & 3 & 6 \\
\hline & Fimbrial & 4 & 8 \\
\hline & Others & 2 & 4 \\
\hline \multirow{4}{*}{ Operation } & Salpingectomy & 43 & 88 \\
\hline & Salpingooprectomy & 4 & 8 \\
\hline & Others & 2 & 4 \\
\hline & Ruptured ectopic & 46 & 94 \\
\hline \multirow[t]{2}{*}{ Out come } & Unruptured ectopic & 2 & 4 \\
\hline & Others & 1 & 2 \\
\hline Blood & Yes & 24 & 51 \\
\hline transfusion & NO & 23 & 49 \\
\hline
\end{tabular}

In $96 \%$ of the cases ectopic pregnancy occurs in the tubes. Among this $82 \%$ occur in the ampulla. Ninety four percent of them came with ruptured ectopic needing emergency blood transfusion. The blood transfusion rate in this study was $55 \%$. The usual surgical treatment in our unit is salpingectomy which accounts for $88 \%$ of the cases. Late diagnoses were key elements leading in almost all cases to major complications and emergency surgical treatments. This is well summarized in table 3 .

\section{DISCUSSION}

Our estimates of ectopic pregnancy in the three years study period in the large managed care Orota Maternity Hospital was quite similar to most of Africa country studies and western countries $(2,5$, and 8$)$.

All women in the reproductive age group who present to a gynecologist or hospital emergency department with lower abdominal pain, with or without vaginal bleeding, have an ectopic pregnancy until proven otherwise. A urinary pregnancy test is mandatory in this clinical situation and if positive, these women should then have a transvaginal ultrasound scan (TVS) performed.

Late diagnoses were important findings that should encourage our physician to promote ectopic pregnancy prevention programs and to improve the care given to women with ectopic pregnancy.EP should be considered a relevant public health indicator in Eritrea, providing an overall picture of the capacity of a health system to deal with the diagnosis and treatment of emergency situations, especially in the field of obstetrics and gynecology.

\section{Limitation of the study}

- Difficulties to assess risk factors from prerecorded log book or an incomplete patient card.

- Few cases of ectopic may be operated as a case of acute abdomen in surgical department.

\section{Reference}

1. Tay JI, Moore J, Walker J. Ectopic pregnancy. BMJ 2000; 320:916-9.

2. Lawson HW, Atrash HK, Saftlas AF, et al. Ectopic pregnancy in the United States, 1970-1986. MMWR CDC SurveillSumm 1989; 38(2):1-10.

3. Ankum WM, Van der Veen F, Hamerlynck JV, et al. Laparoscopy: a dispensable tool in the diagnosis of ectopic pregnancy? HumReprod 1993; 8(8):1301-6.

4. Bouyer $\mathbf{J}$ et al, Sites of ectopic pregnancy: a 10 year population-based study of 1800 cases, Hum Reprod 2002: 17:3224.

5. Leke RJ, Goyaux N, Matsuda T, Thonneau PF. Ectopic pregnancy in Africa: a population-based study, Obstet Gynecol. 2004 Apr; 103(4):692-7.

6. Regional health fórum WHO South East Asia región, Process Documentation of the Initiative to "Improve the Quality of Maternal Health through Implementation of Facility-Based Review of Maternal Deaths",volume 9, 2005

7. Anderson, Frank W. J. MD, MPH; Hogan, Joanne G. PhD; Ansbacher, Rudi MD, MS Sudden Death: Ectopic Pregnancy Mortality.

8. Liberato V. Mukul, MD, Stephanie B. Teal, MD, MPH, Current Management of Ectopic Pregnancy ObstetGynecolClin N Am 34 (2007) 403-419

9. Goyaux $\mathrm{N}$ et al, Ectopicpregnancy in Africad eveloping countries, Acta ObstetGynecolScande, 2003, 82(4): 305-12

10. Centers for Disease control and Prevention (CDC), Ectopic pregnancy-United States, 1990-1992, MMWR, Morb,Mortal,Wkly,Rep1995:44:46 